\title{
Pentingnya Teknik Empati Dalam Proses Konseling Individual
}

\section{The Importance of Empathy Techniques in the Individual Counseling Process}

\author{
Yunita* \\ Fakultas Psikologi, Universitas Medan Area, Indonesia \\ Disubmit: 31 Oktober 2021; Diproses: 31 Oktober 2021; Diaccept: 23 November 2021; Dipublish: 02 Desember 2021 \\ *Corresponding author: E-mail : yunitaa@staff.uma.ac.id
}

\begin{abstract}
Abstrak
Artikel ini menjelaskan tentang pentingnya teknik empati dalam proses konseling individual. Teknik empati adalah menyelaraskan diri (peka) terhadap apa, bagaimana, dan latar belakang perasaan dan pikiran orang lain sebagaimana orang tersebut merasakan dan memikirkannya. Teknik empati merupakan salah satu dari berbagai teknik dalam proses konseling. Sedangkan Proses Konseling adalah proses bantuan yang dilakukan melalui wawancara, yang dilakukan oleh seorang ahli disebut konselor kepada individu yang sedang mengalami suatu masalah disebut konseli apabila di lingkungan formal dan disebut klien apabila diluar lingkungan formal. Tujuan dari dilakukan konseling adalah bermuara pada teratasinya masalah yang sedang dialami. Individual atau sendiri adalah mengenai atau berhubungan dengan manusia secara pribadi yang bersifat perseorangan. Dimana Proses konseling individual hanya dapat dilakukan secara face to face dengan kata lain tidak ada orang lain atau orang ketiga selain dari konselor dan klien. Proses konseling individual tidak hanya dapat dilakukan didalam ruangan melainkan dapat dilakukan diluar ruangan seperti halaman, taman, dan lain-lain. Diharapkan setelah membaca artikel ini dapat melakukan proses konseling individual dengan menggunakan teknik empati secara maksimal dan efektif baik di lingkungan formal, non formal dan informal.
\end{abstract}

Kata Kunci: Teknik Empati; Proses Konseling; Individual

\begin{abstract}
This article explains the importance of empathy techniques in the individual counseling process. Empathy technique is to align oneself (sensitive) to what, how, and the background of other people's feelings and thoughts as that person feels and thinks about them. Empathy technique is one of the various techniques in the counseling process. While the Counseling Process is a process of assistance carried out through interviews, which is carried out by an expert called a counselor to individuals who are experiencing a problem called counselees if they are in a formal environment and are called clients if they are outside the formal environment. The purpose of doing counseling is to solve the problem that is being experienced. Individual or alone is about or relates to humans personally who are individual. Where the individual counseling process can only be done face to face in other words there is no other person or third person apart from the counselor and client. The individual counseling process can not only be done indoors but can be done outdoors such as yards, parks, and others. It is hoped that after reading this article, you can carry out the individual counseling process using empathy techniques to the maximum and effectively in both formal, non-formal and informal environments.
\end{abstract}

Keywords: Empathy Techniques; Counseling Process; Individual

DOI: https://doi.org/10.51849/j-p3k.v2i3.128

Rekomendasi mensitasi :

Yunita (2021), Pentingnya Teknik Empati Dalam Proses Konseling Individual. Jurnal Penelitian Pendidikan, Psikologi dan Kesehatan (J-P3K), 2 (3): 310-315. 


\section{PENDAHULUAN}

Individu adalah seorang; makhluk individu yang khas (terpisah dari yang lain) yang hidup mandiri, secara fisiologis bebas/tidak mempunyai hubungan alamiah satu sama lain. Individu merupakan unit terkecil yang membentuk masyarakat (Sujatmiko, 2014).

Individu berasal dari kata Yunani yakni "individium", yang berarti bersatu. Dalam sosiologi pemahaman individu, tentang karakter dengan kehidupan dan jiwa yang plural, individu mengambil bagian dalam hubungan manusia. Individu adalah substansi yang dibatasi, khususnya sebagai pribadi tunggal, bukan individu secara umum.

Dari perspektif sosiologis, individu adalah subjek yang menyelesaikan sesuatu, subjek yang memiliki jiwa, subjek yang memiliki kemauan, subjek yang memiliki kesempatan, subjek yang memberi arti sesuatu, yang dapat menilai perilakunya sendiri. dan hasil tindakannya. Sederhananya, individu adalah subjek yang bertindak.

Dalam penggunaan cara yang sama, kata pribadi mencakup orang atau benda tertentu dari sebuah perkumpulan. Sampai abad 15, bahkan hari ini, dalam pengertian dan kekuasaan, individu berarti "tak terbagi", dan umumnya menggambarkan setiap artikel nomor tunggal, namun kadang-kadang berarti "seorang individu" (Wikipedia, 2021).

Proses pembimbingan (konseling) adalah suatu program pemberian bantuan yang diwujudkan melalui pertemuanpertemuan pengarahan oleh seorang spesialis kepada orang-orang yang sedang menghadapi suatu masalah dengan niat penuh untuk mengatasi masalah tersebut (Prayitno \& Amti, 2004).

Konseling individu juga diartikan sebagai hubungan timbal balik antara dua orang dimana satu (konselor) berusaha membantu orang lain (klien) untuk sampai pada pemahaman tentang dirinya sendiri sebanding dengan masalah yang dihadapinya nanti (Sukardi, 2002). Konseling individu adalah kunci utama dalam kegiatan menasihati. Proses konseling individu adalah hubungan antara konselor dan klien untuk mencapai tujuan klien, khususnya untuk membantu membangun kembali kesejahteraan psikologis seseorang melalui pengembangan pribadi dan sosial dan berusaha untuk menghapus dampak ketidakharmonisan emosional individu.

Menurut Agus Efendi, empati adalah sikap seseorang untuk memahami orang lain menurut sudut pandangnya, yang jelas-jelas empati dapat mempengaruhi gaya hidup seseorang secara umum, bagi individu yang memiliki empati tinggi pasti akan selalu berusaha memahami pikiran dan perasaan orang lain, yang dapat memberikan beberapa nilai. Empati sangat penting untuk kecerdasan emosional sebagai kapasitas untuk memahami perasaan kita sendiri dan perasaan orang lain, kapasitas untuk memotivasi diri kita sendiri dan kapasitas untuk mengelola perasaan dengan baik dalam diri kita sendiri dan terlibat dengan orang lain (Djafri, 2014).

Empati menurut Batson dalam Franzoi (2006) muncul dengan alasan bahwa mereka perlu membantu orang lain dari penderitaan yang mereka alami (jenis ini disebut altruistic). Ada juga orangorang yang membantu karena mereka 
perlu disebut pahlawan (jenis ini disebut egoistic karena mereka bertindak karena kebutuhan mereka sendiri). Dilihat dari hasil penelitian Davis yang dikutip oleh Franzoi (2003) dikatakan bahwa, orang yang memiliki tingkat empati yang tinggi akan sering mendapat perasaan terpanggil untuk membantu orang lain yang menderita.

Saat ini banyak hal yang terjadi di lapangan, baik dalam situasi formal, nonformal atau in-formal, masih ada konselor yang melakukan proses konseling individu tanpa menggunakan strategi empati, sehingga interaksi konseling individu tidak mengarah pada menangani masalah klien atau konseli. Hal ini dikarenakan konselor tersebut gagal untuk benar-benar melihat bagaimana menggunakan metode empati tersebut, padahal teknik empati sangat penting dalam prosesi konseling individu.

Dari penggambaran di atas, dapat digarisbawahi bahwa pentingnya menggunakan metode empati dalam melakukan konseling individu, untuk menciptakan lingkungan yang aman bagi klien atau konseli saat melakukan konseling individu.

\section{METODE PENELITIAN}

Penulisan ini menggunakan metode deskriptif atas data-data yang dikaji berdasarkan literatur yang terkait dengan masalah kajian. Penulis melakukan komparasi antara literatur dengan pengetahuan. Diantara literatur yang digunakan berupa buku, jurnal, dan artikel di media sosial yang berkaitan dengan pembahasan ini.

Sistematika yang digunakan peneliti dalam penulisan penelitian ini (Zed, 2014), diantaranya ialah: a) mencari kesamaan (Compare) yaitu teknik melakukan review dengan cara mencari kesamaan diantara beberapa literatur \& diambil kesimpulannya; b) memberikan pandangan (Criticize) yaitu teknik melakukan review dengan membuat pendapat sendiri terhadap sumber yang dibaca; c) membandingkan (Synthesize) yaitu teknik melakukan review dengan menggabungkan beberapa sumber menjadi sebuah ide baru; d) meringkas (Summarize) yaitu teknik melakukan review dengan menulis kembali sumbernya dengan kalimat sendiri.

\section{HASIL DAN PEMBAHASAN}

Individu adalah benda atau makhluk yang berdiri bebas dan independen, individu adalah sifat bergantung pada diri sendiri, dan individualisme adalah aliran yang menerima bahwa seseorang tidak membutuhkan orang lain dan semuanya harus dapat dilakukan sendiri.

$$
\text { Konseling individu adalah }
$$

pertemuan konselor dan klien secara perorangan dengan seluk-beluk hubungan membimbing yang dekat dan hangat sehingga konselor dapat memberikan bantuan untuk peningkatan diri klien dan dapat mengatasi masalah yang dihadapinya. Arah dan nasihat diatur menuju sudut positif. Serta konselor berusaha memuaskan klien dengan menciptakan suatu keadaan kondusif yang bermanfaat bagi perkembangan klien sehingga klien dapat mengatasi masalah tersebut setelah ia memahami, mengakui dan memahami potensi dan kekurangannya serta membimbing kemampuannya untuk mengalahkan masalah dan kekurangan (Andriyani, 2018).

Proses konseling individual adalah hubungan antara konselor dan klien yang 
sepenuhnya berniat mencapai tujuan klien. Kewajiban konselor dalam konseling ini adalah mendorong untuk menumbuhkan potensi klien untuk memiliki pilihan agar bekerja secara efektif, produktif dan menjadi manusia mandiri yang teguh dan berkomitmen sehingga klien menjadi individu yang seimbang antara peningkatan intelektual yang menjunjung tinggi pengembangan kreativitas dan produktivitas, sosial emosinal yang menciptakan hubungan yang menyenangkan dengan perasaan yang stabil dan sikap mental yang baik terhadap dirinya sendiri dan dunia luar serta moral religius (Wilis, 2013).

Layanan konseling individu memiliki tujuan untuk membuat klien mandiri dan tidak bergantung pada konselor. Orangorang yang dibimbing setelah ditolong diharapkan untuk menjadi mandiri dengan kualitas utama memiliki pilihan untuk mengenal diri mereka sendiri dan keadaan mereka saat ini sebagaimana adanya, mengakui diri mereka sendiri dan keadaan mereka saat ini secara positif dan dinamis, menetapkan pilihan untuk pribadi dan tanpa bantuan orang lain, dan mewujudkan diri mereka sendiri secara ideal yang ditunjukkan oleh potensi, minat, dan keterampilan terpendam yang mereka miliki (Prayitno \& Amti, 2004).

Menurut Sears, empati dicirikan sebagai sensasi simpati dan bentuk perhatian kepada orang lain, terutama untuk berbagi pengalaman atau secara tidak langsung merasakan penderitaan orang lain (Asih \& Pratiwi, 2010). Hurlock (Asih \& Pratiwi, 2010) menyatakan bahwa empati secara sederhana adalah kemampuan untuk menempatkan pribadi pada posisi orang lain sehingga orang lain tampak seperti bagian bagi diri sendiri. Baron dan Byrne (Asih \& Pratiwi, 2010) menjelaskan bahwa empati adalah kemampuan untuk merasakan kondisi emosi orang lain, merasa simpati dan berusaha untuk mengatasi masalah, dan mengambil sudut pandang orang lain.

Dalam konseling, empati adalah syarat utama untuk memberikan konseling yang efektif. Empati digambarkan sebagai kemampuan konselor untuk memasuki realitas klien, merasakan perasaan klien, Capuzzi dan Gross (Ikiz, 2009). Hal yang sama disampaikan oleh Mappiare (2006) empati membingkai konseling yang kuat dengan kemampuan konselor untuk memasuki sudut pandang klien kadangkadang dianggap emphatic understanding. Mahsudi (2013) menjelaskan bahwa ada dua cara berbeda yang dapat dilakukan oleh konselor pemula untuk menampilkan empati kepada orang lain:

1. Berlatih Empati

a. Catat perasaan baik atau negatif. Jika kita mengalami rasa baik atau buruk, segera catat dengan menuangkannya di jurnal atau saat ini terkenal dengan menulis di blog. Suatu saat, kita dapat membuka rekaman ketika seseorang mengalami hal yang persis sama. Lagi pula, rekaman itu bisa berharga bagi orang lain, yang membacanya ketika dia menghadapi hal yang persis sama, jadi idealnya itu bisa membantu mereka.

b. Memperhatikan curhatan. Biasakan mendengar curhat orang lain sampai selesai dan penuh perhatian. Semakin kita memperhatikan cerita, masalah, dan perasaan orang lain, maka semakin kaya emosi kita. Dalam 
jangka panjang, kita mengetahui tentang bagaimana memahami kekhawatiran dan perasaan orang lain.

c. Membayangkan kejadian dalam diri kita. Mencoba membayangkan sesuatu yang akan kita rasakan saat menghadapi perasaan atau kondisi yang sedang dimiliki oleh orang lain. Sehingga, perasaan serupa muncul, baik yang positif maupun yang negatif, terlepas dari apakah itu marah, sengsara, atau gembira. Itulah cara kita melihat situasi dari sudut pandang orang lain.

2. Lakukan dengan tulus agar kita bersimpati

a. Berhati-hatilah dalam ucapan dan aktivitas. Renungkan perilaku dan kata-kata kita sebelum melakukan atau mengatakannya kepada orang lain. Mungkin perilaku dan kata-kata kita menyakiti orang lain, dan mungkin kita bisa menjadi bijak.

b. Mulailah dengan diri Anda sendiri. Cobalah untuk tidak menasihati orang lain untuk mencapai sesuatu yang kita sendiri tidak mau melakukannya.

c. Memberi bantuan. Memberi bantuan dengan kegiatan menanyakan sesuatu yang bisa kita lakukan untuk membantu seseorang. Bila Anda tidak dapat memberikan sesuatu yang dia minta, cari opsi lain yang berbeda atau mintalah orang lain yang juga dapat membantunya.

Baron dan Byrne mengungkapkan bahwa dalam empati juga terdapat aspek-aspek, yaitu: a) Kognitif, khususnya; Orang yang dapat mengidentifikasi mendapatkan apa yang orang lain rasakan dan mengapa hal itu dapat terjadi pada individu tersebut. b) Afektif, khususnya orang yang mengerti apa yang orang lain rasakan.

Batson dan Coke (Asih \& Pratiwi, 2010) mengungkapkan bahwa dalam empati terdapat aspek-aspek berikut: a) Kehangatan, adalah kecenderungan bahwa seseorang dapat bersikap hangat kepada orang lain. b) Kelembutan, adalah kecenderungan bahwa individu perlu bertindak atau mengungkapkan kata-kata halus terhadap orang lain. c) Peduli, adalah sikap yang dibutuhkan individu untuk memberi perhatian pada orang lain dan lingkungan umum.

Dari kajian teoritis di atas, cenderung dibicarakan sehubungan dengan pentingnya teknik empati dalam proses konseling individual. Telah dikatakan bahwa konselor harus memiliki sikap empati untuk memasuki realitas klien dan memahami perasannya. Hal ini sesuai dengan hasil dari penelitian Clark (2010) bahwa empati ialah hal penting dalam proses konseling, empati diidentifikasi dengan kesadaran konselor tentang perasaannya dan tanggapan batinnya dalam bereaksi dan menghadapi perasaan klien. Melalui pengetahuan individu ini, konselor pengalaman, dalam waktu sebentar, merasakan bagaimana rasanya menjadi klien. Ketika mencoba untuk memahami klien, konselor sejenak dikaitkan dengan interaksi yang mencakup identifikasi, imajinasi, naluri, dan perasaan pada tingkat karakteristik. Seolah-olah, seorang konselor berubah menjadi alat untuk pengaturan empatik dan membingkai spekulasi dalam konteks konseling. Juga, dalam lingkungan sosial, empati adalah keinginan untuk membantu orang lain tanpa memikirkan keuntungan 
mereka sendiri. Empati lebih berpusat pada bantuan kepada pihak lain. Empati yang tinggi pada konselor akan menyebabkan dia mau membantu kliennya, Myers (Asih \& Pratiwi, 2010). Baron dan Byrne (Sutoyo, 2013) memandang empati sebagai syarat untuk membantu memberdayakan munculnya motif altuiristik.

Berdasarkan hasil penelitian yang dilakukan oleh Ira (Dewi, 2020) dikatakan bahwa salah satu cara yang dapat digunakan untuk meningkatkan empati selama proses konseling ialah dengan menerapkan model creative art. Penerapan model ini dapat mengatasi permasalahan kurangnya empati pada konselor yang dapat berdampak pada sulitnya menjalin hubungan interpersonal dengan klien. Sebab efek jangka panjang yang diperoleh dari penerapan model creative art ini ialah akan memperkaya konselor untuk lebih peka terhadap kreatifitas yang dilakukan oleh klien sehingga menciptakan kesadaran dan empati terhadap apa yang dirasakan klien.

\section{SIMPULAN}

Berdasarkan dari paparan di atas, disimpulkan bahwa teknik empati sangat penting untuk dikuasi oleh seorang konselor dalam mengarahkan proses konseling individual untuk menghubungi dan memahami perasaan klien atau konseli secara tepat, sehingga klien atau konseli dapat mengomunikasikan apa yang dia hadapi saat ini secara transparan dan sukarela (tanpa paksaan) dan mendorong penyelesaian masalah bagi konseli atau klien. Hal ini disebut KES (Kehidupan Efektif Sehari-hari).

\section{DAFTAR PUSTAKA}

Andriyani, J. (2018). Konsep Konseling Individual Dalam Proses Penyelesaian Perselisihan Keluarga. Jurnal At-Taujih , 17-31.

Asih, G. Y., \& Pratiwi, M. M. (2010). Perilaku Prososial Ditinjau dari Empati dan Kematangan Emosi. Jurnal Psikologi Universitas Muria Kudus .

Baron, R. A., \& Byrne, D. (2012). Psikologi Sosial Jilid 2. Jakarta: Erlangga.

Clarck, A. J. (2010). Emphaty: An Intergal Model In the Counseling Prosses. Journal of Counseling $\mathcal{E}$ Development .

Dewi, I. K. (2020). Model Creative Art Dalam Konseling Untuk Meningkatkan Empati dan Hubungan Interpersonal pada Mahasiswa Politeknik $\mathrm{LP}_{3} \mathrm{I}$ Medan Kampus Medan Baru. J-P $P_{3} K$, 34-43.

Djafri, N. (2014). Pengantar Pelaksanaan Bimbingan dan Konseling di Sekolah. Gorontalo: Ideas Publishing.

Franzoi, S. L. (2006). Social Psychology. New York: McGraw Hill Companies Inc.

Franzoi, S. L. (2003). Social Psychology zrd Edition. Boston: McGraw Hill Company.

Ikiz, F. E. (2009). Investigation of Counselor Empathy with Respect to Safe Schools. Journal: Science Direct .

Mahsudi, F. (2013). Psikologi Konseling Buku Panduan Lengkap dan Praktis Menerapkan Psikologi Konseling. Yogyakarta: IRCiSoD.

Mapierre, A. (2006). Kamus Istilah Konseling dan Terapi. Jakarta: PT Raja Grafindo Persada.

Prayitno, \& Amti, E. (2004). Dasar-Dasar Bimbingan Konseling. Jakarta: Rineka Cipta.

Qoyyimah, N. R., Noorrizki, R. D., Sa'id, M., Apriliana, J., \& Isqy, T. T. (2021). Efektivitas Konseling Sebaya sebagai Upaya Penguatan Kesehatan Mental Remaja Panti Asuhan. J$P_{3} K, 166-173$.

Sujatmiko, E. (2014). Kamus IPS, Cetakan I. Surakarta: Aksara Sinergi Media.

Sukardi, D. K. (2002). Pengantar Pelaksanaan Bimbingan dan Konseling di Sekolah. Jakarta: Rineka Cipta.

Sutoyo, A. (2013). Bimbingan dan Konseling Islami (Teori $\mathcal{E}$ Praktik). Yogyakarta: Pustaka Belajar.

Wikipedia. (2021, Agustus 28). Pribadi. Diambil kembali dari Wikipedia Ensiklopedia Bebas: https://id.wikipedia.org/wiki/Pribadi

Wilis, S. S. (2013). Konseling Individual Teori dan Praktek. Bandung: Alfabeta.

Zed, M. (2014). Metode Penelitian Kepustakaan. Jakarta: Yayasan Obor Indonesia. 